\title{
El Programa de Cultura del Agua en el noreste de México. ¿Concepto utilitario, herramienta sustentable o requisito administrativo?
}

\author{
María Eugenia González Ávila* \\ María del Socorro Arzaluz Solano*
}

Resumen: El Programa de Cultura del Agua, implantado en Acuña, Coahuila; Nuevo Laredo y Reynosa, Tamaulipas, y en Monterrey, Nuevo León, resulta poco eficaz y eficiente en la mayoría de dichas ciudades. El organismo operador de Nuevo León es el más destacado, ya que se basa más en la experiencia y continuidad de los encargados, que en la obtención de resultados cuantificables. Por lo tanto, es importante considerar dicho programa en las políticas hídricas de México, como una herramienta útil para difundir la cultura del agua, donde se incluyan indicadores cuantificables que permitan evaluar su repercusión y efectividad en la población a corto, mediano y largo plazo, a fin de lograr un uso, manejo y conservación sustentable del recurso, en esta y otras regiones de México.

Palabras clave: cultura del agua, organismo operador, noreste, sustentable.

* El Colegio de la Frontera Norte (COLef).Técnicos \#277 y Río Pánuco, colonia Tecnológico, C. P. 64700. Monterrey, Nuevo León, México. Teléfonos: (81) 8387 4119; 8387 4475; 8387 5503 y 9387 5027. Fax: (81) 8387 4645. Correos electrónicos: megamar@colef.mx / megamarinera@yahoo.com.mx / sarzaluz@hotmail.com

Agradecemos la colaboración de la maestra Isabel Sánchez, técnica académica del colef, para la elaboración del presente artículo; también los comentarios y sugerencias de los dictaminadores que ayudaron a mejorar el documento. 
Abstract: This article analyzes the development of the Programa de Cultura del Agua [Water Culture Program] (PCA) applied in four cities in Northeastern Mexico (Acuña, Coahuila; Nuevo Laredo and Reynosa, Tamaulipas; and Monterrey, Nuevo León). The program is hardly effective or efficient in most of the above cities. Nuevo Leon's utility is the most outstanding, since it is based more on the experience and continuity of the people in charge, rather than on quantifiable results. Therefore, it is important to consider this program as a useful tool of Mexican water policy to propagate a water culture which includes measurable indicators to assess the impact and effectiveness on the population in the short, medium and long term, in order to achieve sustainable use, management and conservation of water resources in this and other regions of Mexico.

Key words: water culture, utility, northeast, sustainable.

\section{Introducción}

El Día Mundial del Agua se conmemora desde 1992, como resultado de la Conferencia de las Naciones Unidas sobre Medio Ambiente y Desarrollo, realizada en Río de Janeiro, Brasil; donde se decidió incrementar los esfuerzos relacionados con el agua, además de mejorar la participación de la mujer para conservar el recurso hídrico y la cooperación internacional para lograr los objetivos de la Declaración del Milenio, anunciada en septiembre del año 2000. El punto número siete fue uno de los que 147 jefes de Estado y 189 naciones se comprometieron a cumplir: el que garantiza la sustentabilidad ambiental del agua, un acceso sostenido a una mejor calidad del líquido para las poblaciones urbanas y rurales, y con ello hacer eficiente su gestión de una manera integrada y con una visión holística, que considere "una cultura de agua sustentable" (Pacheco 2005, 1-2). 
En México, y acorde con la Ley de Aguas Nacionales (LAN) y el Programa de Agua Limpia (PAL), creado en 1991, se proponía incrementar y mantener la calidad del agua mediante cloración y desinfección para cumplir con las condiciones establecidas en la Norma Oficial Mexicana (NOM-127- SSA1-1994); lo cual eleva la calidad de vida de la población (Comisión Nacional del Agua, ConAGUA 2008).

Así, la conagua, mediante el paL envía recursos a los estados y éstos a los municipios, que a su vez los trasfieren en forma directa a los organismos operadores (oo), que los destinan a las actividades siguientes, que integran el Programa de Cultura del Agua (PCA): a) instalación y reposición de equipos de desinfección; b) adquisición y suministro de reactivos químicos y material; c) realizaación de muestreos sistemáticos; d) establecimiento de operativos preventivos contra enfermedades de origen hídrico; e) protección física y sanitaria de fuentes de abastecimiento; f) instalación y operación permanente de espacios de cultura del agua (ECA), para producir y reproducir material didáctico y g) impartición de pláticas escolares y pinta de bardas (Diario Oficial de la Federación, DOF 2003).

En la mayoría de los casos, el PCA se ubica en las unidades de comunicación y cultura del agua o en los departamentos de comunicación de los oo encargados de promover la conservación de los recursos hídricos y la trasmisión de valores en pro del uso racional del agua, a través de estrategias aplicables al entorno local y regional. Sin embargo, autores como González (2003) comentan que la mayoría de las campañas que fomentan la cultura del agua (CA), no son evaluadas y es poco su efecto sobre los hábitos de consumo de la población objetivo, por lo cual considera que no existe una CA verdadera.

Así, a partir de lo anterior y lo detectado durante el proyecto "Gestión local y financiera del agua para uso urbano en la frontera noreste México-Estados Unidos”, auspiciado por el Banco de Desarrollo de América del Norte (BANDAN 2008), surgió la idea de analizar y evaluar el PCA en cuatro municipios y los oo en el noreste de México: Acuña, Nuevo Laredo, Reynosa y Monterrey.

El proyecto consta de seis apartados, el primero describe las etapas del trabajo; el segundo indica las características del área de estudio y de los oo. El punto tres explica el PAL, la estructura y actores 
(instituciones, consejos y organismos) involucrados, y cómo se evalúa dicho programa desde el punto de vista institucional, además se define el concepto de cultura de agua. El apartado cuatro muestra la legislación ambiental aplicada al programa, todo lo anterior sirvió para el análisis y discusión del PCA del punto cinco. La última parte incluye conclusiones acerca de la importancia de elaborar una política pública específica para el PCA, donde se consideren indicadores cualitativos y cuantitativos que permitan conocer su repercusión a corto, mediano y largo plazo, y donde la cA se convierta en una herramienta útil dentro de los indicadores de gestión del agua.

\section{Metodología}

Comprende una serie de visitas y evaluación de los departamentos, espacios o áreas en que se aplica el PCA y se entrevistó a sus coordinadores en Acuña (Sistema Municipal de Agua y Saneamiento, SIMAS); Monterrey (Sistemas de Agua y Drenaje de Monterrey, SADM); Reynosa y Nuevo Laredo (Comisión de Agua, COMAPA). Además se consultó información relacionada en internet y otra se obtuvo de los oo. También se identificó a los actores.

El área de estudio

En Acuña, Monterrey, Reynosa y Nuevo Laredo la temperatura varía entre muy seca y templada subhúmeda (véase figura 1). En Coahuila y Nuevo León el clima es muy seco, mientras que en Tamaulipas predomina el seco y templado subhúmedo. La excepción es una porción equivalente a menos de 3 por ciento de la franja fronteriza (en su extremo noreste), donde el clima es subhúmedo, aunque en 96 por ciento de la frontera noreste impera el seco (estepario) y muy seco (desértico), de manera casi homogénea (Instituto Nacional de Ecología-Secretaría de Medio Ambiente y Recursos Naturales, INE-SEMARNAT 1998, 25-35).

La mayoría de los cuerpos de agua en esta región presentan un grado alto de sobrexplotación (CONAGUA 2008). Así que la fuente principal de abastecimiento para uso urbano de los municipios en 


\section{Figura 1}

Ubicación de los municipios y ciudades fronterizas

del noreste México

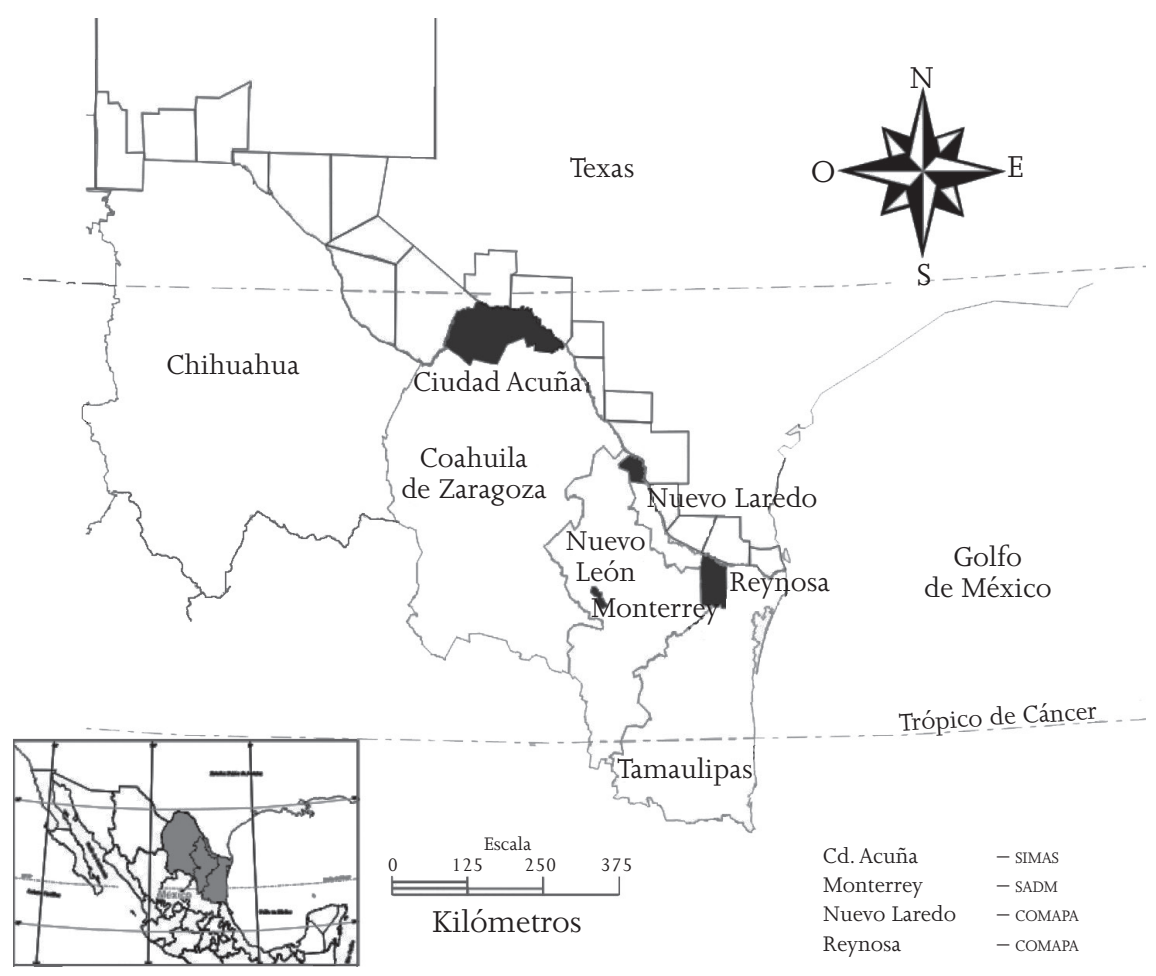

Fuente: elaboración propia.

estudio proviene del río Bravo y de otras fuentes secundarias (véase figura 2).

En lo que se refiere a los usuarios de agua potable, en Monterrey, la cobertura del oo es estatal, lo cual tiene implicaciones en cuanto al servicio y gestión, a diferencia de lo que ocurre en Acuña, Nuevo Laredo y Reynosa, que es municipal y donde las tomas domiciliarias son menos (véase figura 3). 


\section{Figura 2}

Características hidrográficas de las entidades en estudio

\begin{tabular}{|l|l|}
\hline Entidad & Descripción \\
\hline Coahuila & $\begin{array}{l}\text { El arroyo El Caballo alimenta la presa de La Amistad. Al norte pasa } \\
\text { el río Bravo, que sirve como límite entre México y Estados Unidos. } \\
\text { Los arroyos El Caballo, El León y Palomos constituyen las cuencas } \\
\text { intermedias del río Bravo. Al sureste se encuentra la laguna El } \\
\text { Centenario, la cual se comparte con el municipio de Jiménez. }\end{array}$ \\
\hline Nuevo León & $\begin{array}{l}\text { El río Santa Catarina cruza Monterrey, por lo general está seco, } \\
\text { pero en época de lluvia su corriente es caudalosa y ha provocado } \\
\text { inundaciones. Hoy su sistema hidrológico se sustenta en mantos } \\
\text { acuíferos de Santa Catarina, Villa de Santiago, Mina y China, } \\
\text { entre otros. }\end{array}$ \\
\hline Tamaulipas & $\begin{array}{l}\text { Su única fuente es el río Bravo o Grande del norte, que sirve } \\
\text { de línea divisoria entre México y Estados Unidos. Además, } \\
\text { tiene dos derramaderos naturales, el arroyo del Coyote, } \\
\text { al sur de La Alazana, al oeste otros arroyos de menor importancia } \\
\text { como El Laguito, El Estero Reventado, El Abandonado, } \\
\text { La Sandra, El Ortillo, El Carrizo, Aguas Negras, El Gobierno, } \\
\text { El Ramireño y La Cedena. }\end{array}$ \\
\hline
\end{tabular}

Fuente: elaborado a partir de información de la Enciclopedia de municipios de México (EMM 2005a, b, c y d).

\section{Figura 3}

Número de tomas domiciliarias por municipio

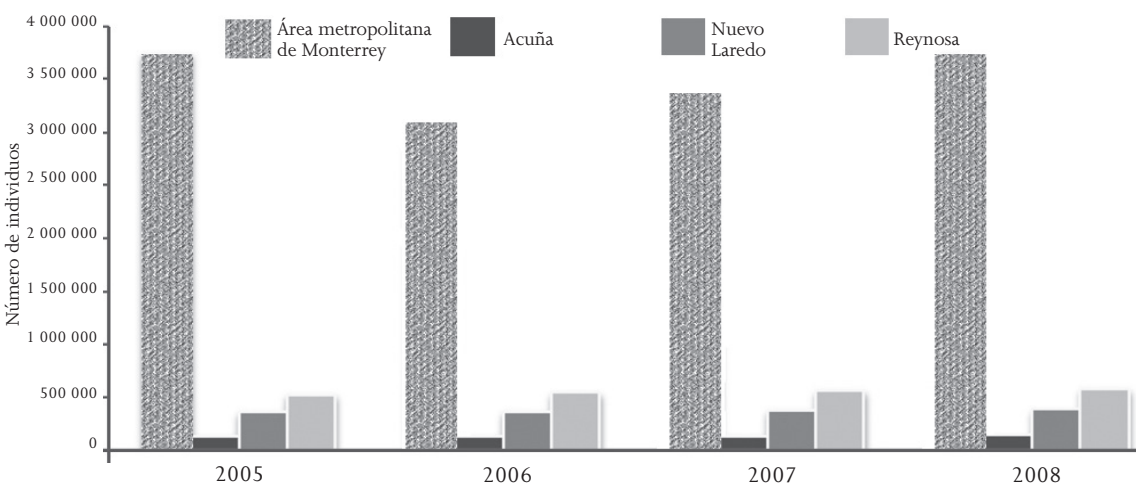

Fuente: CONAGUA (2009a). 


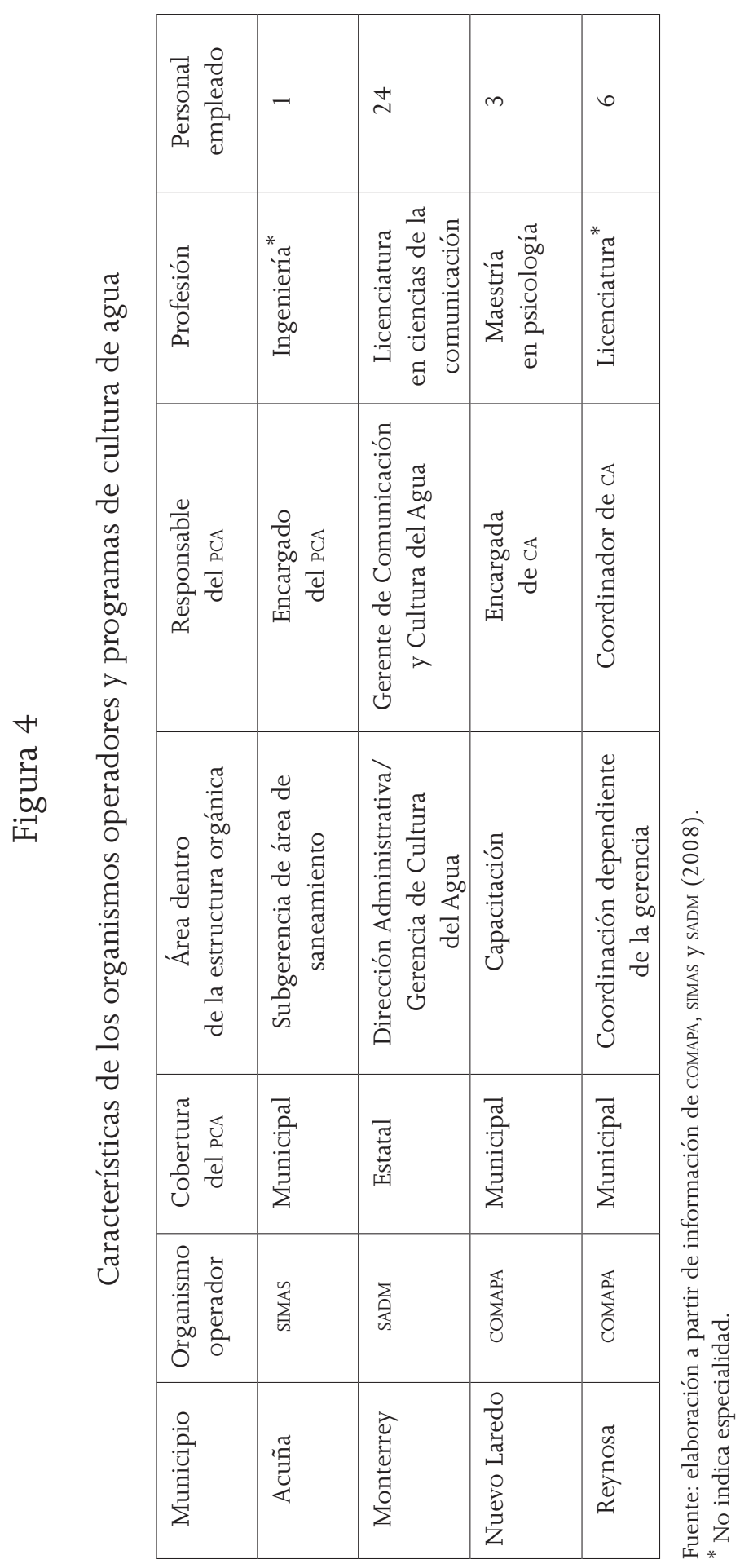


Organismos operadores de ciudades del noreste

En Acuña, el SIMAS proporciona los servicios de agua y drenaje. En 2007 el padrón de usuarios era de 37 529, de los cuales 35963 eran domésticos, 1491 comerciales y 75 industriales (SIMAS 2008; EMM 2005a).

En Nuevo Laredo, la Comapa se encarga de brindar los servicios de agua y drenaje; se estableció en 2002, y en 2007 atendía a 107609 usuarios, en su mayoría domésticos, es decir, 95 565, con un consumo de $2507111 \mathrm{~m}^{3}$. En Reynosa la COMAPA también está a cargo del agua potable y el drenaje (EMM 2005c y d).

En Nuevo León, el SADM abastece agua al total de la población estatal, y por tanto es el oo con mayor cobertura entre los estudiados; cuenta con más usuarios y personal en la Dirección Administrativa/ Gerencia de Cultura del Agua en el PCA (véase figura 4).

En lo referente a indicadores de gestión del agua, el oo mejor situado es el SADM, mientras que la COMAPA-Reynosa está en situación opuesta (véase figura 5).

\section{Programas Agua Limpia y de Cultura del Agua, y la Cultura del Agua (CA)}

Programa de Agua Limpia (PAL)

A partir de 1990, en la Cumbre Mundial a favor de la infancia, México adquirió el compromiso de elaborar programas en los campos de la salud, nutrición, educación y ayuda a los niños, con el fin de elevar sus posibilidades de supervivencia y bienestar; ello implicaba realizar gestiones y acciones para brindar agua de buena calidad a los infantes, y evitar enfermedades gastrointestinales asociadas al consumo de agua no potable como las ocurridas en 1991 (ConAGUA 2009a). En este mismo año, el Poder Ejecutivo federal instituyó el PAL, y se suscribió un convenio de colaboración para la prevención y control del cólera entre la conagua y la entonces Secretaría de Salubridad y Asistencia, cuyo objetivo era llevar a cabo operativos preventivos y emergentes, que atendieran los problemas de cólera, 


\section{Figura 5}

Valor promedio de indicadores de la gestión del agua, 2005-2008

\begin{tabular}{|c|c|c|c|c|}
\hline Indicador & Acuña & Monterrey & Reynosa & $\begin{array}{l}\text { Nuevo } \\
\text { Laredo }\end{array}$ \\
\hline Toma con servicio continuo (\%) & 100.0 & 100.0 & 100.0 & $\mathrm{n} / \mathrm{d}^{*}$ \\
\hline Redes e instalaciones (\%) & 93.3 & 100.0 & $\mathrm{n} / \mathrm{d}$ & 97.3 \\
\hline Padrón de usuarios (\%) & 97.5 & 100.0 & 100.0 & $\mathrm{n} / \mathrm{d}$ \\
\hline Macromediciones (\%) & 100.0 & 100.0 & $\mathrm{n} / \mathrm{d}$ & 100.0 \\
\hline Micromediciones (\%) & 80.2 & 100.0 & 64.7 & 82.1 \\
\hline Reclamaciones (\#) & 0.6 & 87.0 & 145.1 & $\mathrm{n} / \mathrm{d}$ \\
\hline Costos entre volumen producido $\left(\$ / \mathrm{m}^{3}\right)$ & 3.6 & 6.4 & 8.4 & 6.4 \\
\hline Empleados por cada mil tomas (\#) & 3.4 & 4.2 & 6.7 & $\mathrm{n} / \mathrm{d}$ \\
\hline $\begin{array}{l}\text { Empleados dedicados } \\
\text { al control de fugas (\#) }\end{array}$ & $\mathrm{n} / \mathrm{d}$ & 8.1 & 8.6 & $\mathrm{n} / \mathrm{d}$ \\
\hline Dotación (litros/hora/día) & 276.7 & 244.1 & 255.8 & 369.0 \\
\hline Eficiencia física (\%) & 45.0 & 73.0 & 62.8 & 53.3 \\
\hline Eficiencia comercial (\%) & 74.2 & $\mathrm{n} / \mathrm{d}$ & 70.4 & 59.1 \\
\hline Eficiencia de cobro (\%) & 86.0 & 81.0 & 68.9 & 93.6 \\
\hline Rehabilitación de toma domiciliaria (\%) & 9.6 & 6.5 & $\mathrm{n} / \mathrm{d}$ & $\mathrm{n} / \mathrm{d}$ \\
\hline $\begin{array}{l}\text { Presión de suministro del agua en la red } \\
\text { (metro de columna de agua, m.c.a.) }\end{array}$ & 5.0 & 20.0 & $\mathrm{n} / \mathrm{d}$ & 13.8 \\
\hline Consumo (litros/hora/día) & 191.2 & 178.2 & 170.0 & 279.4 \\
\hline Relación de trabajo (\%) & 102.4 & 101.6 & 93.5 & 100.2 \\
\hline Eficiencia global (\%) & 28.7 & $\mathrm{n} / \mathrm{d}$ & 45.8 & 30.8 \\
\hline ** Programa de cultura del agua (años) & 2 & 28 & 1 & 10 \\
\hline
\end{tabular}

* No disponible.

** Información obtenida de COMAPA, SIMAS y SADM (2008).

Fuente: Instituto Mexicano de Tecnología del Agua (IMTA) (2010), Programa de información de los oo.

de lo cual surgieron el PAL y PCA como instrumentos conceptuales (Ibid. 2008).

El objetivo principal del PaL es impulsar, consolidar y fortalecer la cultura del buen uso y preservación del agua en coordinación con estados y municipios, a través de la creación de los espacios de cultura del agua (ECA) fijos e itinerantes, que formulan y ejecutan programas relacionados con la CA (Ibid. 2008). 
En 1996, al darse la descentralización del PAL con un esquema federalizado incipiente sin reglas de operación, se establecieron las primeras bases para su trasferencia a los estados. En 1998, la ejecución de las acciones y las contrataciones pasaron en forma directa a la coordinación y administración de cuenca hidrológica de las gerencias regionales (Ibid. 2008). En 2001 se publicaron las primeras reglas de operación del PAL, como preludio para trasferir las funciones a los gobiernos estatales, lo cual se reflejó en el presupuesto, que aumentó de 18 por ciento en 2001 a 80 en 2002, en forma de subsidios. El resultado fue la acción operativa del PAL, que evolucionó en dos líneas de atención: la federal, mediante subsidios a los gobiernos estatales y la regional, encargada del funcionamiento del PCA (Ibid. 2009a).

En la actualidad, el PAL nacional cuenta, además de los ECA, con 13 espacios móviles de cultura del agua (EMCA); vehículos automotores con equipo audiovisual, de cómputo, mobiliario, carpas y material didáctico y generadores portátiles de energía eléctrica, que son una opción para ampliar las actividades educativas con respecto al recurso agua, a través de foros culturales alusivos a la importancia del vital líquido y el cuidado del medio ambiente (Ibid. 2009d y e).

Estos EMCA son operados y atendidos por las direcciones generales de los organismos de cuenca (oc) que, al igual que las direcciones locales de la CONAGUA, producen material lúdico y audiovisual y organizan y participan en eventos de CA (véase figura 6). Además, tiene a su cargo la formación y capacitación de promotores del ECA y del PCA en comunidades indígenas, rurales y zonas urbanas marginadas (Ibid. 2009e y d).

La evaluación del PAL se realiza en función de los componentes siguientes: a) índice de morbilidad y mortalidad; b) cobertura de desinfección de las aguas suministradas; c) fuentes de abastecimiento protegidas y d) número de habitantes beneficiados con operativos preventivos. Aunque el componente ca sólo se evalúa por la cantidad de participantes en pláticas escolares y comunitarias, así como el número de asistentes a los ECA; es decir, los espacios se miden en función de la atención a su audiencia, pero no considera el efecto del mensaje de CA en la población objetivo; que en algunos casos aunado a una mala administración del servicio del agua resulta en 
Figura 6

Actividades del Programa de Cultura del Agua, 1999 - 2006

\begin{tabular}{|c|c|c|c|c|}
\hline Año & $\begin{array}{c}\text { Espacios de cultura del agua } \\
\text { instalación y operación }\end{array}$ & \multicolumn{2}{|c|}{ Pláticas } & Escolares \\
\hline 2001 & $153^{*}$ & 2581 & 1549 & 1014 \\
\hline 2002 & 218 & $\mathrm{n} / \mathrm{d}$ & $\mathrm{n} / \mathrm{d}$ & $\mathrm{n} / \mathrm{d}$ \\
\hline 2003 & 271 & 2813 & 1923 & 1167 \\
\hline 2004 & 256 & 2978 & 1860 & 1498 \\
\hline 2005 & $\mathrm{n} / \mathrm{d}^{* *}$ & $\mathrm{n} / \mathrm{d}$ & $\mathrm{n} / \mathrm{d}$ & $\mathrm{n} / \mathrm{d}$ \\
\hline 2006 & 227 & 3988 & 2296 & 1652 \\
\hline
\end{tabular}

* Espacios municipales del agua

** No disponible

Fuente: elaborado a partir de información consultada en CONAGUA (2008).

el nulo ahorro y mal uso del recurso. Algo semejante ocurre con los PCA del IMTA y la CONAGUA (González 2003).

Las valoraciones del PAL, realizadas por la CONAGUA y el IMTA de 2005 a 2008 (CONAGUA 2006a y b; 2007) hacen referencia a que se deben realizar campañas verdaderas de CA, además de la falta de un marco normativo para el establecimiento y funcionamiento de los ECA, así como para su cumplimiento, el cual se deja a criterio y voluntad de los ejecutores (gobierno y municipios); a los que en ocasiones les falta experiencia y presupuesto.

De manera práctica, la evaluación del PCA se realiza mediante una cédula, que considera tres aspectos: a) si el ECA está habilitado y operando; b) si cuenta con equipo y mobiliario para el fin deseado y c) si cumple el programa anual de operación, tal como lo marcan las reglas. Sin embargo, el componente ca sólo se mide con los asistentes a las pláticas (CONAGUA 2006a y b), pero no se cuantifica el efecto de los programas en la población. Tal como se ha hecho en Perú (Delgado y Ramírez 2008), donde se aplicó una metodología cualitativa y cuantitativa, que comprendió dinámicas grupales y entrevistas a profundidad, se evaluó la efectividad del PCA, el conocimiento y percepción de la gente acerca del tema. Por su parte, Sandoval et al. (2002) realizaron un estudio de opinión sobre CA e 
imagen institucional, e indicaron que debe estar encaminado a lo local; tener una base de planeación y elaborar índices de impacto porque la CA es sólo un componente en la gestión del agua.

Actores gubernamentales del Programa de Cultura del Agua

La estructura del PCA se divide en el Plan de Desarrollo Nacional, el Programa Sectorial del Medio Ambiente y Recursos Naturales y Plan Nacional Hídrico (PNH). Donde los actores nacionales y regionales del PAL y el PCA son los OC como ejecutores, las instancias estatales y los oo. En tanto que la SEMARNAT y CONAGUA, aun cuando son parte del proceso y están dentro del marco legislativo, participan como rectoras y vinculadoras entre el municipio y oo con el oc (véase figura 7); además de facilitar la obtención de los recursos económicos y logísticos para cumplir con el PAL y contar con ECA (véase figura 8).

A escala nacional, el PNH establece para 2007 a 2012, la educación en materia del buen uso y cuidado del agua como una de las premisas esenciales del gobierno actual. Se argumenta que detonar una nueva cultura del agua y generar conciencia en torno a ella, el cuidado del medio ambiente y los recursos naturales son fundamentales para garantizar a la población una calidad adecuada de vida (PNH 2008, 86). Sin embargo, para lograr estos objetivos se requiere impartir pláticas escolares y comunitarias, incorporar conceptos clave en los libros de texto, abrir espacios municipales de CA y establecer fórmulas novedosas de acercamiento a la sociedad. El objetivo cinco del PNH indica: "Consolidar la participación de los usuarios y la sociedad organizada en el manejo del agua y promover la cultura de su buen uso", para lo cual se contemplan nueve estrategias, que involucran a los cc y la sociedad civil (Ibid.).

A escala regional, el programa se ejecuta a través de la Subgerencia de Cultura del Agua adscrita a la Coordinación General de Atención Institucional, Comunicación y Cultura del Agua, en cooperación con las direcciones generales de los oc, direcciones locales y unidades administrativas para su ejecución, que se promueven y concentran en los gobiernos estatales y municipales donde se crean los ECA; se capacita y asesora a sus responsables. Las acciones por rea- 
lizarse en cada entidad quedan definidas por los convenios de coordinación y sus anexos técnicos de ejecución respectivos asignados por la conagua y los representantes de los gobiernos locales. Para lo cual la federación aporta 50 por ciento de los recursos fiscales necesarios para ejecutar los trabajos concertados (CONAGUA 2009a).

\section{Figura 7}

Estructura orgánica en gestión del agua

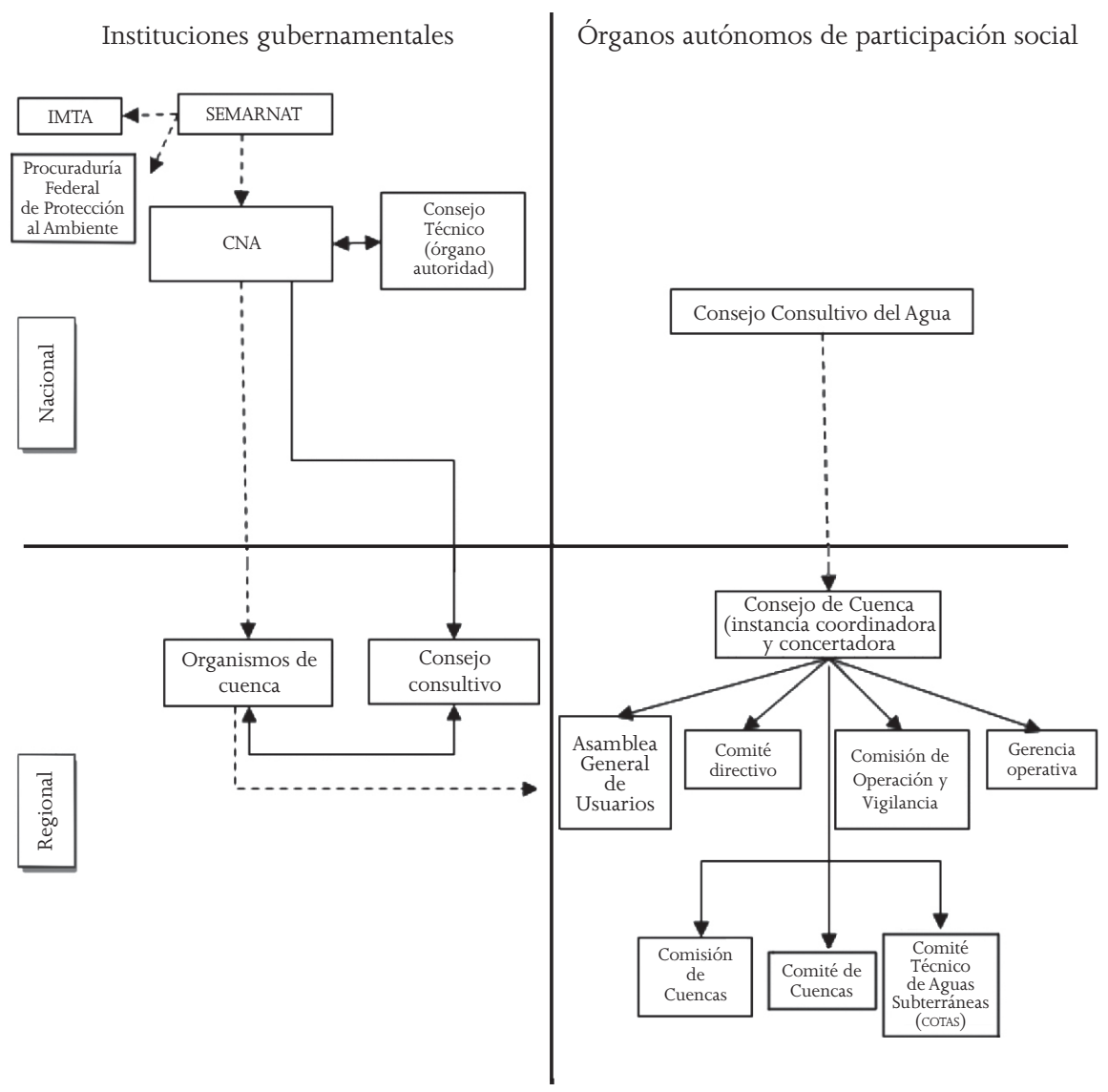

Fuente: elaboración propia, a partir de información de SEMARNAT (2009) y CONAGUA (2009). 


\section{Figura 8}

\section{Funciones de las instituciones relacionadas con los programas de cultura del agua}

\begin{tabular}{|c|c|}
\hline Institución & Función \\
\hline SEMARNAT & $\begin{array}{l}\text { Fomentar la protección, restauración y conservación de los } \\
\text { ecosistemas y recursos naturales y bienes y servicios ambientales, } \\
\text { con el fin de propiciar su aprovechamiento y desarrollo sustentable } \\
\text { (Ley Orgánica de la Administración Pública, artículo } 32 \text { bis } \\
\text { reformada en el Dof del } 25 \text { de febrero de 2003). Donde queda } \\
\text { incluida el agua y junto con otras instituciones se fomentará la } \\
\text { cultura del agua, acorde con lo establecido en el PNH 2007-2012. }\end{array}$ \\
\hline CONAGUA & $\begin{array}{l}\text { Lograr un cambio positivo y proactivo en la participación individual } \\
\text { y social en torno al uso sustentable del agua, para no perjudicar } \\
\text { a las generaciones siguientes; incidir en el o los procesos de } \\
\text { comunicación a través de los cuales la sociedad se allega } \\
\text { información desde la educación formal y no formal } \\
\text { (familia, medios de comunicación, capacitación) y espacios } \\
\text { de participación social para establecer la ca. }\end{array}$ \\
\hline $\begin{array}{l}\text { Consejos de Cuenca } \\
\text { (cc) }\end{array}$ & $\begin{array}{l}\text { Formular y ejecutar programas que tiendan a mejorar la } \\
\text { administración de las aguas nacionales. Construir la } \\
\text { infraestructura hidráulica necesaria y coadyuvar en la } \\
\text { conservación y restauración de las cuencas hidrográficas. }\end{array}$ \\
\hline $\begin{array}{l}\text { Consejo Consultivo } \\
\text { del Agua (CCA) }\end{array}$ & $\begin{array}{l}\text { Apoyar y articular la participación social con el fin de realizar } \\
\text { una gestión integral y el manejo sustentable del agua en México. } \\
\text { Los objetivos del cCA son: a) promover, generar y difundir } \\
\text { conocimiento; b) propiciar transparencia y rendición de cuentas; } \\
\text { c) emitir opiniones y formular propuestas de política pública; } \\
\text { d) difundir y promover el cumplimiento de la ley y e) crear, } \\
\text { producir y difundir mensajes y campañas educativas } \\
\text { para sensibilizar y conscientizar a la población } \\
\text { sobre la problemática del agua. }\end{array}$ \\
\hline COTAS & $\begin{array}{l}\text { Auxiliar del cc, sin estar subordinado de él, en el diseño y ejecución } \\
\text { de estrategias para lograr la gestión equilibrada de su acuífero. } \\
\text { Sus tareas son: a) elaboración del subprograma hídrico } \\
\text { para la gestión del acuífero; b) monitoreo cercano del } \\
\text { comportamiento de los pozos; c) gestión de estudios } \\
\text { hidrogeológicos, y la aportación de información para su realización; } \\
\text { d) vigilancia para garantizar el manejo adecuado de los pozos } \\
\text { y las concesiones; e) diseño, gestión y evaluación de proyectos } \\
\text { locales para la recarga intencional; f) elaboración de propuestas } \\
\text { para el reordenamiento de pozos y g) elaboración } \\
\text { del reglamento del acuífero. }\end{array}$ \\
\hline
\end{tabular}

Fuente: elaborado a partir de CCA (2009), SEMARNAT (2009) y LAN (2004). 
Las estrategias relacionadas en forma directa con la CA son:

- Crear conciencia entre la población sobre la necesidad del pago y uso responsable y eficiente del agua. Los indicadores son las campañas nacionales trasmitidas en medios de comunicación sobre la importancia, buen uso y pago del recurso.

- Informar oportuna y eficazmente sobre la escasez del agua, los costos de proveerla, su uso responsable y valor económico, sanitario, social y ambiental, a través de boletines, versiones estenográficas y otros materiales institucionales disponibles para el público en el portal de internet de la conaGua.

- Impulsar programas de educación y comunicación para promover la $\mathrm{CA}$, e incorporarla en los libros de texto de primaria, que se refieran al tema ambiental y creación de espacios para fomentarla, en este caso el universo o meta ideal serían 2590 espacios; en 2006 fueron 1120 y el objetivo para 2007-2012 son 1470.

- Posicionar el agua como un recurso estratégico y de seguridad nacional, así como implantar los programas de CA en las 32 entidades federativas del país.

Como se observa en el texto anterior, se trata sólo de intenciones que no se respaldan con normas e indicadores que puedan cuantificarse. Ejemplo de ello son los informes trimestrales que se solicitan a los oo, que en ocasiones no existen o es imposible consultar con facilidad, ni verificar la información contenida y menos la veracidad de sus datos dentro del PCA.

Aunado a lo anterior está la falta de participación social, que constituye un obstáculo para la gestión de los recursos hídricos, por ello es importante reforzar la conciencia y cooperación social en el PCA. Todo esto a fin de que cada individuo sea capaz de reflexionar, participar y decidir acerca del uso y manejo del agua. Al tiempo que se realiza y proponen acciones reales en su entorno colectivo, como una forma de empleo sustentable del recurso local. Sin embargo, el uso del líquido se ha alejado del interés de la ciudadanía, e incluso la comunidad se ha vuelto indiferente ante la problemática, además no ha cambiado su comportamiento para reconstruir su relación con el agua, mientras que los esfuerzos de los oo han sido insuficientes para fortalecer el PCA. 
Evaluación de los programas de cultura del agua

En México es muy reciente la experiencia de la evaluación, y hay pocos antecedentes en cuanto a las políticas públicas de programas examinados para observar sus alcances, detectar fallas e implantar estrategias de mejoramiento. De tal forma que el tema se institucionalizó a partir de la promulgación de la Ley General de Desarrollo Social y la creación del Consejo Nacional de Evaluación de la Política de Desarrollo Social (CONEVAL), y como consecuencia hay gran cantidad de programas sin parámetros oficiales de evaluación y mucho menos se conocen sus alcances, a pesar de tener años funcionando, como sucede con el PCA.

No obstante, estos ejercicios son importantes y necesarios, pues sirven para medir o apreciar el desempeño de los instrumentos de las políticas, y fomentar el consenso entre los actores interesados. Esto se hace mediante un proceso social de aprendizaje, que comprende el análisis de los criterios empleados para evaluar la efectividad de las medidas adoptadas, en función de los problemas que se intenta abordar con una política específica (Subirats 1995, 5).

En forma general, la evaluación significa:

[...] una forma de investigación social aplicada, sistemática, planificada y dirigida: encaminada a identificar, obtener y proporcionar de manera válida y fiable, datos e información suficiente y relevante, en que apoyar un juicio acerca del mérito y el valor de los diferentes componentes de un programa (tanto en el diagnóstico, programación o ejecución) o de un conjunto de actividades específicas que se realizan, han realizado o realizarán, con el propósito de producir efectos y resultados concretos, comprobando la extensión y el grado en que dichos logros se han dado, de forma tal que sirva de base o guía para una toma de decisiones racional e inteligente entre cursos de acción, o para solucionar problemas o promover el conocimiento y la comprensión de los factores asociados al éxito o fracaso de sus resultados (Ziccardi y Saltalamacchia 1997, 26). 
Al considerar lo anterior, la evaluación cumple los criterios siguientes:

- Es una tarea de investigación social aplicada

- Debe ser sistemática, planificada y dirigida

- Los datos obtenidos deben ser válidos y confiables

- Debe estar encaminada a obtener datos e información relevante en qué apoyar un juicio acerca del mérito y valor de los componentes de un programa, (tanto en la fase de diagnóstico como en la programación o ejecución) o de un conjunto de actividades específicas; sobre programas o tareas en curso, otras que se hayan realizado o las que se ejecutarán

- El objetivo es comprobar la extensión y el grado en que se han dado dichos logros, y servir de base o guía para tomar decisiones racionales, como solucionar problemas o promover el conocimiento o la comprensión de los factores asociados al éxito o fracaso de sus resultados (Ibid., 27).

Un especialista indica que las evaluaciones permiten incrementar la eficiencia y favorecer que exista un principio de equidad en la elaboración de políticas sociales (Cohen y Franco 2003, 25). Es decir, se establece el proceso evaluativo como un paso necesario, con el fin de mejorar su cobertura. En la literatura clásica, los tipos de evaluación se agrupan en función de varios criterios: a) el tiempo de su realización, b) los objetivos que se persiguen, c) quiénes las realizan, d) la naturaleza que poseen, e) la escala que asumen y f) los agentes a los que van dirigidas. De tal manera que se reconocen los siguientes:

- En función del momento en que se realiza y los objetivos que persiguen, las evaluaciones pueden ser:

a) Ex ante

b) Ex post, ${ }^{1}$ que se divide en la de procesos y de impacto

\footnotetext{
${ }^{1}$ La primera se realiza antes de comenzar el proyecto, la segunda cuando ya está en ejecución o ha concluido.

Los métodos más usuales en la evaluación ex ante son el análisis costo-beneficio (ACB y el costo-efectividad (ACE). Sin embargo, "el ACB es más adecuado para analizar proyectos
} 
- En función de quien la realiza es:

a) Externa: por personas ajenas a la organización

a) Interna: dentro de la organización gestora del proyecto

c) Mixta: combina las otras dos formas

d) Participativa: busca minimizar la distancia entre el evaluador y los beneficiarios, se utiliza para proyectos pequeños (Ibid., 115)

- En función de la escala, la evaluación puede ser para proyectos: ${ }^{2}$

a) Grandes

b) Pequeños

- En la función de los destinatarios, la evaluación va dirigida a:

a) Directivos superiores

b) Administradores

c) Técnicos (Ibid., 119)

Tampoco se debe olvidar que en la evaluación de los programas sociales existe el problema de la utilización correcta de los recursos, es decir, que el dinero se emplee de la mejor manera, para atender los objetivos para los que fueron creados. En este aspecto se encontraron muchas fallas en las formas usadas por las instancias centrales para medir los efectos del PCA sobre la población, donde los aspectos por observar son el número de personas atendidas, las charlas impartidas o, como en el caso de SADM, la disminución en el consumo aun con el aumento de usuarios. Si se considera los tipos de evaluación aceptados, ninguno de los criterios constituye una valoración en el sentido estricto, pues aún no se han realizado ni establecido los lineamientos científicos para la medición del efecto de esta clase de programas en los usuarios.

económicos y el ACE presenta mayores potencialidades para evaluación de proyectos sociales" (Ibid., 109).

En torno al criterio ex post, la evaluación de procesos determina la medida en que los componentes de un proyecto contribuyen a los fines perseguidos. Busca detectar las dificultades disminuyendo los costos de la eficiencia, se trata asimismo de una evaluación periódica.

Por otra parte, la evaluación de impacto busca apreciar en qué medida el proyecto alcanza sus objetivos y cuáles son sus efectos secundarios (Ibid., 112).

${ }^{2}$ De acuerdo con Cohen y Franco, aquí es donde se pueden encontrar las mayores diferencias en el tipo de herramientas utilizables para realizar una evaluación cuantitativa o cualitativa. Para definir si un proyecto es grande o pequeño se consideran el número de personas involucradas y la magnitud de los recursos requeridos. 
De tal manera y ante la ausencia de pautas de evaluación del PCA, en este documento se advirtieron algunos elementos de la forma en que los oo ejercen los recursos, se trata de observaciones empíricas presentadas en forma comparativa, para ayudar a construir criterios que puedan retomarse cuando se fije una política más estricta en este sentido. Para empezar, el marco legal que sostiene al programa en ningún momento establece que deberá evaluarse, ni observa la responsabilidad de cada uno de los involucrados.

Concepto de cultura del agua

La CA es un proyecto de educación ambiental cuya finalidad es hacer conciencia sobre la protección y uso del agua (Murillo 2006, 3436). Sin embargo, el concepto $\mathrm{CA}$ ha desatado una gran polémica en torno a las implicaciones de llamarlo así; también como nueva cultura del agua (término nacido en España), desarrollo de capacidades y aprendizaje social o de cualquier otra forma análoga, lo que ha provocado el surgimiento de corrientes de pensamiento que han confluido y concordado en que es inaplazable la construcción de formas nuevas de relacionarse con el entorno, con los recursos naturales y en general con el resto de los seres del planeta (Ibid.).

El concepto de CA manejado por la Organización de las Naciones Unidas para la Educación, la Ciencia y la Cultura, UNESCO (2008) propone dividirlo en su palabra base, es decir, abordar primero la cultura como el patrimonio común de un pueblo, con características únicas en su manifestación, y en esencia como organizadora de hábitos, pautas y habilidades de los individuos, que es al mismo tiempo ordenada y reclasificada por ellos. Así, se puede llamar cultura a los modos o formas de ser (pensar, sentir, decir, obrar), del hacer y vivir de los pueblos. Otro concepto más de CA es el conjunto de creencias, conductas y estrategias comunitarias para el uso del agua, que puede "ser leída" en las normas, formas de disponer los conocimientos, prácticas y objetos materiales que la comunidad da o acepta tener. En tanto, el tipo de relación entre las organizaciones sociales, que tienen el poder y los procesos políticos, se concreta en relación con el aprovechamiento, uso y protección del líquido (Ibid.). 
Otra definición de ca la considera un

conjunto de modos y medios utilizados para la satisfacción de necesidades fundamentales relacionadas con el agua y con todo lo que dependa de ella. Incluye lo que se hace con el agua, en el agua y por el agua para ayudar a resolver la satisfacción de algunas de estas necesidades fundamentales. Se manifiesta en la lengua, en las creencias (cosmovisión, conocimientos), en los valores; en las normas y formas organizativas; en las prácticas tecnológicas y en la elaboración de objetos materiales; en las creaciones simbólicas (artísticas y no artísticas); en las relaciones de los hombres entre sí y de éstos con la naturaleza y en la forma de resolver los conflictos generados por el agua (Vargas 2006).

Por lo tanto, la ca es un aspecto específico de la cultura de un colectivo que comparte, entre otras cosas, una serie de creencias, valores y prácticas respecto a ella. Es importante destacar que la CA está ligada a un colectivo (grupo étnico o cultura) e instrumentos conceptuales existentes, es posible identificar el tipo de aporte del grupo y registrar su procedencia. Hoy en día se sabe que no existe la "pureza cultural", porque la cultura está construida sobre los sincretismos y migraciones, intercambios y adaptaciones de las personas. Sin embargo, cada vez más se están valorando los conocimientos agrícolas, científicos, técnicos, ecológicos y medicinales como productos de sistemas que pertenecen a grupos específicos (Ibid.).

En resumen, la CA promueve la adquisición de conocimientos sobre el medio ambiente, la transformación de actitudes, el cultivo de hábitos y valores que faciliten la construcción hacia la sustentabilidad y el mejoramiento de la calidad de vida de los habitantes de la nación, con base en una cultura ambiental que signifique una forma nueva de pensar, vivir y sentir. Dicho concepto debe estar articulado a diferentes proyectos y acciones realizados en instituciones y organismos públicos, privados y sociales. Además, debe incorporar el componente cultural a las políticas públicas relacionadas con el agua; así como hacer referencia en los programas y proyectos nacionales, estatales y locales relacionados con el recurso hídrico. Y también impulsar la participación social responsable y crítica en 
la gestión integrada del agua. Por ello, el concepto de cA debe ser claro e incluir elementos sociales, económicos y ambientales, que lo lleven a ser viable y sustentable desde su concepción y aplicación. $\mathrm{Al}$ respecto, en la figura 8 se propone un modelo conceptual con base en lo anterior.

Figura 8

Conceptualización de cultura de agua

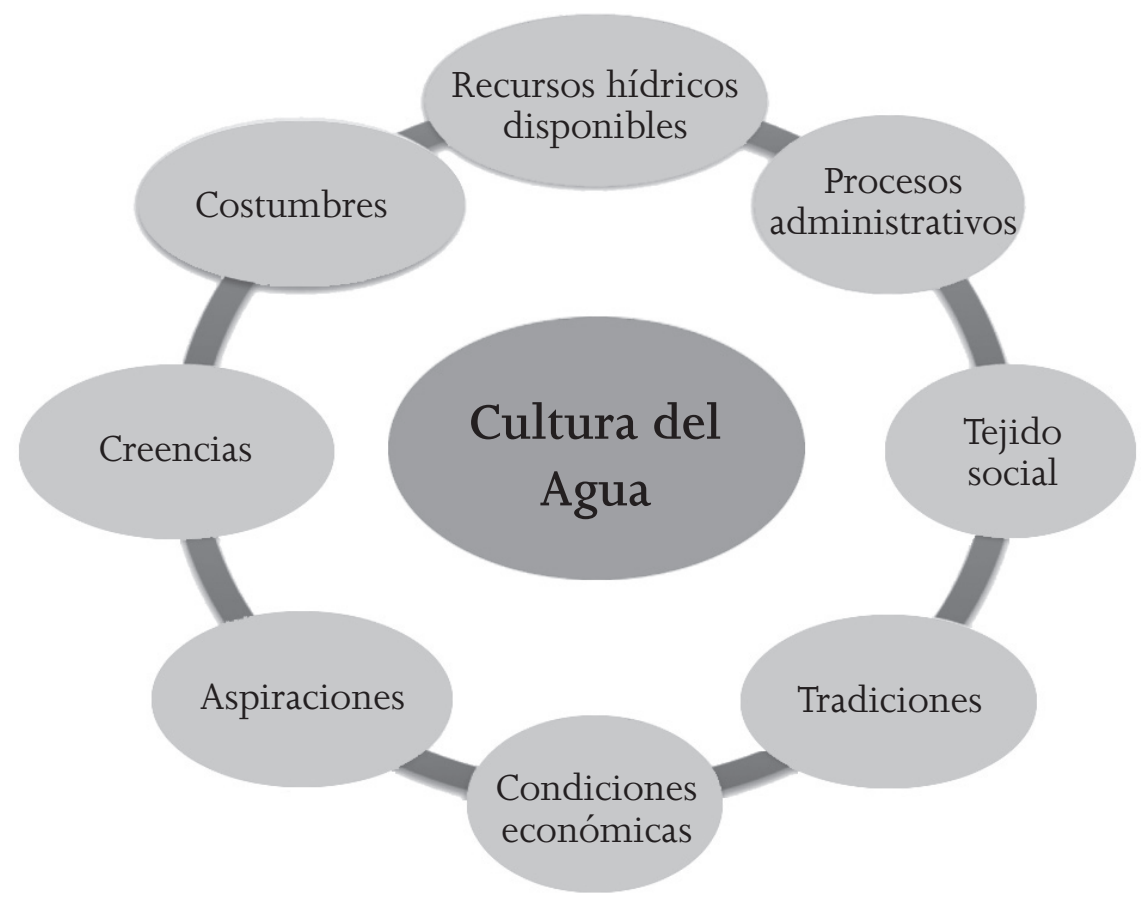

Fuente: elaboración propia.

Leyes y reglamentos involucrados en el Programa de Cultura del Agua

El marco jurídico que involucra al PAL y CA incluye a la Ley de Aguas Nacionales en su capítulo v bis y artículos implícitos (véase figura 
9 ), además de muchas instituciones, consejos y comités. En términos reales, la conAGUA, junto con el oc deberían promover entre la población, autoridades y medios de comunicación la cA, pero en la práctica los municipios y sus oo son los que realizan la función, con recursos de instancias federales y estatales.

Las tareas que los oo deben llevar a cabo son: a) coordinarse con las autoridades educativas federales y estatales, para incorporar la CA en los programas de estudio de todos los niveles educativos; b) instrumentar campañas permanentes de difusión sobre la CA; c) informar a la población sobre la escasez del agua, los costos de proveerla y su valor económico, social y ambiental; d) fomentar el uso racional y conservación del recurso como tema de seguridad nacional y e) promover el interés de la sociedad para participar en la gestión de los recursos hídricos.

Sin embargo, la legislación referida denota falta de coordinación y claridad en su interacción, que se diluyó cuando la conagua le dio a la cA la categoría de subprograma. Así, en 2004 se contaba con una estructura programática nueva con independencia presupuestal y normativa interna, lo que derivó en divergencias de acciones concretas para aplicarlo, como se advirtió en los lugares estudiados (CONAGUa 2009d). Por lo que en la actualidad los oo y el municipio son los encargados de elaborar el PAL y PCA, y depende de los recursos económicos estatales, y aunque no se notan los cambios políticos que ocurren cada tres años, que repercuten en el PCA, éste no resulta atractivo para los gobiernos municipales, pero sí es un requerimiento que se debe cumplir ante los oc y la CONAGUA.

Algunas otras leyes relacionadas con el PCA incluyen a los medios masivos de comunicación para la difusión del tema y la promoción de la CA entre la población infantil (véase figura 10), acorde con lo dispuesto por la Ley Federal de Radio y Televisión (LAN 2004). Dichas leyes hacen referencia a que tanto la SEMARNAT como la CONAGUA, en coordinación con los oc, se encargarán de promover el mejoramiento del PCA entre la población, gobierno y medios de comunicación, acorde con la realidad del país y sus regiones hidrológicas. Al tiempo que se apoyan en las autoridades educativas federales y estatales para incorporar en los planes de estudio de todos los niveles educativos los conceptos de Ca (Ibid.). Sin embargo, ya en la 


\section{Figura 9}

Extractos de leyes y artículos relacionados con el PCA

\begin{tabular}{|c|c|}
\hline Regulación & Definición \\
\hline $\begin{array}{l}\text { Ley de Aguas } \\
\text { Nacionales }\end{array}$ & 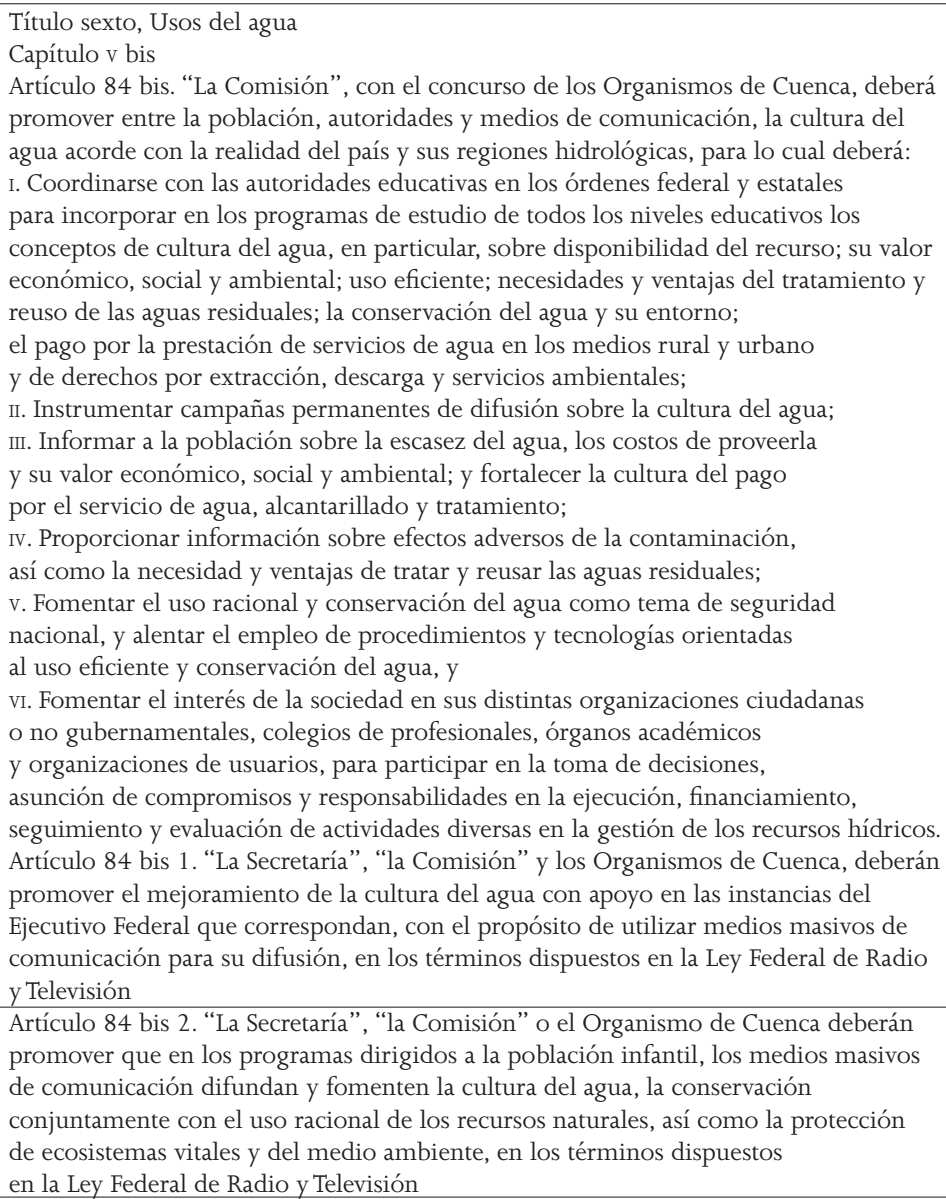 \\
\hline $\begin{array}{l}\text { Leyes de agua } \\
\text { de Coahuila }\end{array}$ & $\begin{array}{l}\text { Ley de Aguas para los Municipios del Estado de Coahuila de Zaragoza } \\
\text { Capítulo tercero.- de la organización y administración de los sistemas municipales } \\
\text { de aguas y saneamiento } \\
\text { Capítulo I.- disposiciones generales (artículo 12) } \\
\text { Capítulo III.- de la organización y administración de los sistemas municipales de aguas } \\
\text { y saneamiento (artículo xiv) } \\
\text { Capítulo vi.- de las tarifas (artículo 76) }\end{array}$ \\
\hline Nuevo León & $\begin{array}{l}\text { Ley de Agua Potable y Saneamiento para el Estado de Nuevo León; Capítulo II } \\
\text { Administración de los servicios públicos de agua potable y saneamiento (artículo 6) }\end{array}$ \\
\hline Tamaulipas & $\begin{array}{l}\text { Ley de Aguas del Estado de Tamaulipas; Capítulo III. De la Comisión Estatal del Agua } \\
\text { de Tamaulipas (artículo 6. Son atribuciones de la Comisión, XLI, Xxxix), Capítulo IV } \\
\text { de los ayuntamientos (artículo 18, xxII). Título octavo de la cultura del agua; } \\
\text { Capítulo I. Uso eficiente y cuidado del agua (artículo 167, xII) }\end{array}$ \\
\hline
\end{tabular}

Fuente: elaborado a partir de información de la LAN (2004) y Ley de Agua del Estado de Tamaulipas (2009); Ley de Agua Potable y Saneamiento para el Estado de Nuevo León (2009); Ley de Aguas para los Municipios del Estado de Coahuila de Zaragoza (2009). 


\section{Figura 10}

\section{Extracto de disposiciones de coordinación en materia de cultura del agua}

\begin{tabular}{|c|c|}
\hline Regulación & Definición \\
\hline \multirow[t]{4}{*}{$\begin{array}{l}\text { Ley de Aguas } \\
\text { Nacionales }\end{array}$} & $\begin{array}{l}\text { Artículo 9. "La Comisión" es un órgano administrativo desconcentrado de } \\
\text { "la Secretaría", que se regula conforme a las disposiciones de esta Ley y sus reglamentos, } \\
\text { de la Ley Orgánica de la Administración Pública Federal y de su Reglamento Interior. } \\
\text { Son atribuciones de "la Comisión" en su Nivel Nacional, las siguientes: } \\
\text { xxvi. Promover en el ámbito nacional el uso eficiente del agua y su conservación en } \\
\text { todas las fases del ciclo hidrológico, e impulsar el desarrollo de una cultura del agua que } \\
\text { considere a este elemento como recurso vital, escaso y de alto valor económico, social } \\
\text { y ambiental, y que contribuya a lograr la gestión integrada de los recursos hídricos }\end{array}$ \\
\hline & $\begin{array}{l}\text { Artículo } 12 \text { bis 6. Los Organismos de Cuenca, de conformidad con los lineamientos que } \\
\text { expida "la Comisión", ejercerán dentro de su ámbito territorial de competencia } \\
\text { las atribuciones siguientes: xv. Promover en coordinación con Consejos de Cuenca, } \\
\text { gobiernos de los estados, organizaciones ciudadanas o no gubernamentales, } \\
\text { asociaciones de usuarios y particulares, el uso eficiente del agua y su conservación } \\
\text { en todas las fases del ciclo hidrológico, e impulsar una cultura del agua que considere } \\
\text { a este elemento como un recurso vital, escaso y de alto valor económico, social } \\
\text { y ambiental y que contribuya a lograr la gestión integrada de los recursos hídricos }\end{array}$ \\
\hline & $\begin{array}{l}\text { Artículo } 13 \text { bis } 3 \text {. Los Consejos de Cuenca tendrán a su cargo: } \\
\text { v. Promover la participación de las autoridades estatales y municipales y asegurar la } \\
\text { instrumentación de los mecanismos de participación de los usuarios de la cuenca } \\
\text { y las organizaciones de la sociedad, en la formulación, aprobación, seguimiento, } \\
\text { actualización y evaluación de la programación hídrica de la cuenca o cuencas } \\
\text { de que se trate en los términos de ley; } \\
\text { xI. Contribuir a la valoración económica, ambiental y social del agua; } \\
\text { xviII. Participar en el mejoramiento de la cultura del agua como recurso vital } \\
\text { y escaso, con valor económico, social y ambiental; } \\
\text { xx. Integrar comisiones de trabajo para plantear soluciones y recomendaciones } \\
\text { sobre asuntos especíicos de administración de las aguas, desarrollo de infraestructura } \\
\text { hidráulica y servicios respectivos, uso racional del agua, preservación de su calidad } \\
\text { y protección de ecosistemas vitales }\end{array}$ \\
\hline & $\begin{array}{l}\text { Artículo } 14 \text { bis. "La Comisión”, conjuntamente con los Gobiernos de los estados, } \\
\text { del Distrito Federal y de los municipios, los organismos de cuenca, los consejos } \\
\text { de cuenca y el Consejo Consultivo del Agua, promoverá y facilitará la participación } \\
\text { de la sociedad en la planeación, toma de decisiones, ejecución, evaluación y vigilancia } \\
\text { de la política nacional hídrica; } \\
\text { Iv. Celebrará convenios de concertación para mejorar y promover la cultura del agua a } \\
\text { nivel nacional con los sectores de la población enunciados en las fracciones anteriores } \\
\text { y los medios de comunicación, de acuerdo con lo previsto en el Capítulo v del Título } \\
\text { Sexto de la presente Ley, y Artículo } 14 \text { bis } 3 \text {. El Instituto Mexicano de Tecnología del } \\
\text { Agua es un organismo público descentralizado sectorizado a "la Secretaría", que tiene } \\
\text { por objeto, de acuerdo con su instrumento de creación y estatuto orgánico, realizar } \\
\text { investigación, desarrollar, adaptar y transferir tecnología, prestar servicios tecnológicos } \\
\text { y preparar recursos humanos calificados para el manejo, conservación } \\
\text { y rehabilitación del agua y su entorno, a fin de contribuir al desarrollo sustentable. } \\
\text { (...) xiI. Promover la educación y la cultura en torno al agua que fomente en la } \\
\text { sociedad la conciencia de que el líquido es un bien escaso que requiere del cuidado } \\
\text { de su cantidad y calidad, así como de su aprovechamiento sustentable y de la mitigación } \\
\text { de sus efectos indeseables, y ...Título Tercero. Política y Programación Hídricas, } \\
\text { Capítulo Único, Sección Primera. Política Hídrica Nacional } \\
\text { Artículo } 14 \text { bis } 5 \text {. Los principios que sustentan la política hídrica nacional son: } \\
\text { xxi. La cultura del agua construida a partir de los anteriores principios de política hídrica, } \\
\text { así como con las tesis derivadas de los procesos de desarrollo social y económico }\end{array}$ \\
\hline
\end{tabular}

Fuente: elaborado a partir de información de la Ley de Aguas Nacionales (2004) y conagua (2009a). 
práctica la SEMARNAT no coopera ni participa en forma directa en el programa, y tampoco la conAGUA, que sólo actúa como rectora del proceso y su involucramiento es poco claro, mientras que el oc es el que más participa en el PCA; seguido por la representación estatal y el oo.

Así, aunque la LAN considera a todas las instancias referidas, en la mayoría de los casos las instituciones actúan de manera independiente, como los Oc, cc y COTAS, que no están subordinados a la coNAGUA, y son órganos colegiados de integración mixta, regidos por la LAN, pero con reglamento propio. Mientras que la función del IMTA es educar y elaborar material didáctico (LAN 2004).

\section{Análisis del PCA en cuatro ciudades del noreste de México}

Con respecto a los resultados y análisis del PCA, de cada oo de los municipios visitados, primero se explica la situación en cada uno, acorde con la información obtenida en las entrevistas, y después se analiza la efectividad de los indicadores de gestión de 2005 a 2008, que pudieran reflejar alguna acción.

En las visitas y entrevistas al personal encargado o relacionado con el PCA se encontraron diferencias sustanciales en varios rubros y en la atención al programa. Se consideraron elementos como lugar en la estructura administrativa, profesionalización, personal empleado y la transparencia en la información, entre otros. De tal forma que, por ejemplo en Acuña, el PCA está dirigido por un ingeniero químico, quien además atiende las plantas de potabilización y, con el auxilio esporádico de dos personas, realiza las actividades relacionadas a la CA. Él tiene más de diez años encargándose de varios programas, y debido a la variedad de sus tareas, al PCA le dedica alrededor de 20 por ciento del tiempo efectivo de trabajo. Si bien hay voluntad y disposición del personal a cargo, no se cuenta con una capacitación específica en materia de CA, no hay evaluación ni presupuesto fijo.

En el COMAPA de Acuña se imparten pláticas escolares, se organizan visitas guiadas a las plantas de tratamiento y se ofrecen charlas 
acerca del sistema de tratamiento, todo con apoyo en el material didáctico que proporciona CONAGUA, además de algunas iniciativas propias. No obstante la cantidad de trabajo del personal, que incluye saneamiento, drenaje y atención a los laboratorios (por citar algunas funciones), además realiza las actividades que conciernen al PCA.

En Reynosa, en el momento de la entrevista acababa de cambiar la estructura administrativa, por la alternancia de partido político en el gobierno (del Partido Acción Nacional al Revolucionario Institucional), por lo que cuando se realizaron las visitas el equipo que se encargaría de la CA se estaba integrando. La coordinación nueva depende del gerente de COMAPA, y está conformada por seis personas. De la poca información recabada, el objetivo del PCA en este municipio es "fomentar el buen uso y cuidado del agua en los diversos ámbitos sociales y generacionales, por medio de programas enfocados a brindar un servicio social de cultura y apoyo a las comunidades que nos requieren como gestores ante autoridades de COMAPA". Se imparten pláticas de cultura del agua; también existe el programa comapa Apoya a tu Escuela y el Centro Integral de Atención Ciudadana ${ }^{3}$ que recibe notificaciones de desperdicio de agua. No obstante, falta más información sobre el contenido de estas actividades, y esto, aunado al cambio en la administración, hizo casi imposible evaluar el programa, lo cual resulta preocupante sobre todo para municipios como Reynosa, que además de contar con recursos hídricos escasos, presenta problemas de contaminación y una población que aumenta en forma alarmante.

En Nuevo Laredo lo que ha dado algunos resultados es sobre todo la continuidad en el cargo de la persona dedicada al PCA, quien lleva en este puesto más de diez años. Dicho programa se ubica en la Dirección de Capacitación, dependiente del gerente de COMAPA; donde trabaja una psicóloga con un asistente y una secretaria, todos con cargos de confianza. Al igual que en los casos anteriores, las actividades principales han sido las charlas en escuelas y visitas guiadas a las plantas de tratamiento. Destacan varios elementos a favor: la antigüedad en el puesto, que proporciona mayor conocimiento sobre las tareas, la iniciativa de la encargada por innovar y trabajar

\footnotetext{
${ }^{3}$ www.reynosa.gob.mx
} 
aun con presupuesto escaso y el apoyo de la gerencia en turno, que le permite capacitarse y que el PCA se lleve a cabo aun cuando no hay claridad de su efecto en la población. Por otro lado se observan problemas como la falta de atención exclusiva al programa, ya que esta área se dedica a cuestiones relacionadas con cursos y capacitación del personal del oo, el reconocimiento escaso de las demás secciones de la administración sobre las tareas de un programa de este tipo, el presupuesto raquítico y entregado siempre en el último momento y el exceso de trabajo que exige la capacitación, que le resta tiempo a la CA.

Cabe destacar que tener más años en el cargo ha beneficiado, ya que con el tiempo se han podido establecer alianzas tanto con la población a quien va dirigido el programa: maestros y directivos de escuelas, como hacia adentro de la administración, de tal manera que es uno de los pocos municipios en Tamaulipas que elabora materiales propios y que ha abierto dos ECA, lo cual es positivo debido a lo extenso del territorio.

Nuevo Laredo es quizá el municipio más apegado a los requerimientos solicitados por CONAGUA para los ECA; por ejemplo, en 2007 se impartieron 144 pláticas a escolares y se atendieron 9948 alumnos (información proporcionada por el titular del PCA de Nuevo Laredo, en 2008). No obstante, si bien es uno de los pocos casos con estadísticas precisas sobre la población atendida, no ha realizado aún la medición del efecto de estas actividades en su población.

En el SADM de Nuevo León, que se ha denominado como ejemplo exitoso a seguir para el resto de los oo en materia de ECA y del PCA, los factores principales que han contribuido a su expansión son la continuidad del programa y la estabilidad laboral de la persona encargada, la profesionalización de toda la dirección a cargo y la permanencia en los demás puestos de este organismo, situación inusual en las administraciones locales en México.

Este programa comenzó en 1986, a raíz de una gran sequía en la región, y entonces se empezó a pensar en la importancia de la comunicación efectiva para trasmitir el valor del agua, y fue cuando se le asignaron recursos especiales. No obstante, durante la década de 1980 las campañas sólo se hacían de julio a octubre, es decir, en la temporada más crítica del año. El PCA ha pasado por varias etapas 
y ha tenido diversas denominaciones: Programa de Uso Eficiente, Cultura del Agua y Cultura del Agua y Saneamiento. Su objetivo actual es sensibilizar a la gente del cambio de hábitos en torno al agua y la estrategia principal es segmentar el mercado para realizar campañas específicas de acuerdo con cada parte. La estructura del SADM está compuesta por las direcciones de administración, operación, comercial, finanzas, contraloría interna, saneamiento e ingeniería. El PCA depende de la dirección administrativa, cuenta con mucho personal y varias certificaciones; se considera una especie de empresa pública con lógica privada, que ha logrado posicionarse a escala nacional.

Es notable el alto grado de profesionalización de esta área en el oo del estado, que a diferencia de los casos anteriores, cuenta con 24 personas a cargo de las áreas de monitoreo de medios, pláticas escolares, relaciones públicas, programas rurales, diseño gráfico y apoyo. Destaca la permanencia en el puesto tanto de la encargada, como de casi todo el personal; hablar de 28 años dice mucho de la experiencia adquirida, y es una situación pocas veces vista en la administración local en México. Además, la titular de Comunicación y Cultura del Agua en Monterrey preside al mismo tiempo la Asociación Nacional de Cultura del Agua (ANCA), integrada por casi quinientos empleados de diversos organismos operadores en todo el país, preocupados por el cuidado del agua.

El Programa de Cultura del Agua en Monterrey está estrechamente vinculado con la estrategia de comunicación social del oo, de tal forma que quien dirige la CA a la vez se encarga del manejo institucional del organismo, se trata de la vocera e imagen oficial del SADM. Una de sus tareas es el monitoreo constante de los medios para responder las demandas continuas. Por otra parte, existe un programa institucional de relaciones públicas, en el cual se establecen nexos con empresas, organizaciones no gubernamentales y escuelas, lo que permite llevar el PCA a diferentes sectores.

El logro principal de la empresa ha sido la apertura de los ECA en los 51 municipios de Nuevo León, asimismo hay campañas de verano, visitas escolares y celebraciones especiales, etcétera. Esto ha llevado a que SADM trate de cubrir los requerimientos en el PCA del estado; por ejemplo, de 2007 a 2008 impartió 155660 pláticas es- 
colares y 4743 comunitarias; capacitó a 7667 maestros; presentó 82 exposiciones y ofreció 32 visitas a instalaciones hidráulicas. Además de las 170 conferencias para público en general y la trasmisión de 16696 anuncios radiofónicos y televisivos, que es un indicio de la capacidad económica y cobertura de esta área del SADM. Esto se justifica si se considera que sólo en 2006 el SADM recibió 636 mil pesos de CONAGUA y otra suma igual del estado para establecer su PAL (CONAGUA 2009a). El caso de Monterrey es reconocido a escala nacional, por tratarse de una empresa funcional en muchos sentidos, sus buenas prácticas llevaron a considerarla por la Escuela de Graduados en Administración Pública y Política Pública (EGAP) como un ejemplo del manejo adecuado del agua en localidades urbanas (EGAP 2006, 43-49).

A pesar de todos los aspectos positivos enumerados, los indicadores que utiliza el PCA de Monterrey no resultan adecuados para saber si tiene un efecto significativo sobre los habitantes del estado, ya que la mayoría del trabajo lo realiza en torno a los municipios cercanos. Si bien se trata de cifras significativas, si se considera la magnitud, antigüedad y personal empleado en el PCA del oo de Monterrey, en comparación con los casos anteriores, esto dista mucho de ser una evaluación de la repercusión en materia de ahorro del recurso y efectividad en la estrategia de comunicación empleada. La información proporcionada por el oo cita como evidencias benéficas la reducción del consumo promedio mensual en las tomas domésticas, que pasó de $18.82 \mathrm{~m}^{3}$ en 1997 a $17.40 \mathrm{~m}^{3}$ en 2006, y que a pesar de un incremento de 48.9 por ciento de usuarios en los últimos 11 años, el suministro sólo aumentó 12 por ciento. ${ }^{4}$

No obstante los datos proporcionados, no pueden considerarse una prueba de la efectividad de programa por sí mismo o como resultado de la aplicación de varias acciones simultáneas, sin antes hacer un estudio que verifique la eficacia de cada práctica, que a la fecha no se ha realizado, y que a varios años de iniciado el programa debería ser prioritario. El SADM es el único de los oo analizados que cuenta con una certificación por cumplimiento de la Norma Técnica Laboral COAs.0228.01 referente a "difusión de la empresa

\footnotetext{
${ }^{4}$ www.sadm.gob.mx
} 
de agua y saneamiento y promoción de la cultura del agua”, que expide el Consejo Nacional de Normalización y Certificación de Competencias Laborales, CONOCER (2009). Sin embargo, no hubo pruebas de que se cumpliera con las "unidades de competencia laboral", donde se señale que deben realizarse acciones para establecer, diseñar y evaluar la repercusión del PCA en la población objetivo.

Así, entre las cuatro ciudades revisadas, Nuevo Laredo y Monterrey pueden considerarse como las que mejor se apegan a la difusión y promoción del PCA. Mientras que en Reynosa y Acuña el cambio de gobierno y los recursos económicos escasos, así como la poca importancia brindada al PCA han propiciado que los ECA sólo se cumplan en papel (véase figura 11).

Figura 11

Evaluación cualitativa de infraestructura y recursos humanos por municipio

\begin{tabular}{|l|c|c|c|c|c|c|c|}
\hline Municipio & $\begin{array}{c}\text { Existen } \\
\text { ECA }\end{array}$ & $\begin{array}{c}\text { Equipo y } \\
\text { material } \\
\text { para el PCA }\end{array}$ & $\begin{array}{c}\text { Material } \\
\text { didáctico } \\
\text { propio }\end{array}$ & $\begin{array}{c}\text { Personal } \\
\text { capacitado }\end{array}$ & $\begin{array}{c}\text { Certificación } \\
\text { laboral } \\
\text { (cOAS-0228) }\end{array}$ & $\begin{array}{c}\text { Presupuesto } \\
\text { propio }\end{array}$ & $\begin{array}{c}\text { Actividades } \\
\text { extras } \\
\text { al PCA }\end{array}$ \\
\hline Acuña & 0 & 0 & 0 & 0 & 0 & 0 & 1 \\
\hline Reynosa & 0 & 0 & 0 & 0 & 0 & 0 & 0 \\
\hline $\begin{array}{l}\text { Nuevo } \\
\text { Laredo }\end{array}$ & $1^{*}$ & 1 & 1 & 1 & 0 & 0 & 1 \\
\hline Monterrey & 1 & 1 & 1 & 1 & 1 & 1 & 1 \\
\hline
\end{tabular}

$1=$ sí y $0=$ no.

* En Nuevo Laredo se han construido dos espacios, en Nuevo León hay uno en cada municipio de la entidad.

Fuente: elaboración propia, a partir de la información de SIMAS, SADM, COMAPA Reynosa y Nuevo Laredo.

En lo que respecta al PAL nacional, aun cuando se han efectuado evaluaciones específicas de desempeño, en 2008 y 2009, y otras de consistencia y resultados, no se tienen indicadores de medición de la efectividad del PCA. El análisis del CONEval de 2008, acerca de la difusión de las evaluaciones a los programas sociales por secretaría y entidad como la CONAGUA, han calificado al PCA con 82 por ciento y 
al PAL con 78, esto al considerar las deficiencias en información que contiene la página de internet, es decir, la falta de datos del equipo evaluador; tanto generales de las unidades administrativas responsables del seguimiento de la evaluación como de la contratación. ${ }^{5}$ Así, dicha evaluación no da indicios, hace falta una herramienta para medir la efectividad de los espacios de cultura del agua y el programa de cultura del agua dentro del programa agua limpia y la única información solicitada por la CONAGUA se refiere al número de escuelas, alumnos, maestro y comunidad que recibió la información del PCA, pero no existe una forma factible de evaluar su eficiencia y eficacia, como disminución del consumo, reuso de agua, decremento en pérdida de líquido por fugas, entrevistas directas al usuario u otras.

En cuanto a los indicadores de gestión de los cuatro oo estudiados (véase figura 4), el SADM presentó los mejores resultados de 2005 a 2008. Aunque el efecto del PCA no se ve reflejado en una disminución en el consumo, que es superior a los 7.5 litros per cápita por día, que indica la Organización Mundial de la Salud, oms (2010). Por lo cual sería importante complementar dichos indicadores con la información obtenida de la evaluación de la repercusión del PCA, lo cual podría ser una herramienta para determinar la eficiencia y eficacia del oo en la gestión, que por ejemplo en Reynosa tiene los peores valores en cuanto a las acciones en torno al PCA, tal como quedó en evidencia en la presente investigación.

\section{Conclusiones}

A casi tres décadas del famoso comercial televisivo de "ciérrale", en el que participaba un gordito simpático, o la frase "gota a gota el agua se agota”, que indicaba por qué ahorrar agua, no ha surgido un programa de ahorro importante, esto quizá debido a que los programas de cultura del agua no han cumplido el objetivo de impulsar, consolidar y fortalecer el buen uso y preservación del recurso. Además, no ha habido un cuestionamiento serio sobre por

\footnotetext{
${ }^{5}$ www.coneval.gob.mx
} 
qué no se han logrado cambiar los malos hábitos de desperdicio de la población y las deficiencias en materia de gestión de los oo. Hace falta la consolidación de actitudes positivas en torno al uso y manejo de agua, que debe tener un componente cognitivo que consolide la creencia y mire con buenos ojos ese hábito, y otro que lleve a ejecutar esa práctica positiva.

Resulta indispensable que los programas de cultura del agua se tomen como una política pública verdadera, es decir, que exista un conjunto de decisiones coordinadas cuyo objetivo sea la distribución del recurso a toda la población de manera equitativa, sin que se perjudique o privilegie a un grupo, individuo o ecosistema determinado. Dicha disposición debería ser lo suficientemente robusta como para ser evaluada con resultados medibles que se reflejen en el ahorro, consumo y eficiencia en uso y manejo de este recurso e incluso considerarse como parte de los indicadores de gestión del agua, sobre todo en regiones desérticas como las del norte del país.

De la presente investigación se desprende que en ninguno de los casos analizados se realiza una evaluación seria de la efectividad del PCA y el cumplimiento de sus objetivos con todos los elementos que esto conlleva. Para ello es necesario involucrar a los gobiernos locales, estatales y federal y a la población, para cumplir de manera cabal con este programa.

Según lo observado y consultado en los municipios estudiados, el tema depende más de la voluntad personal del encargado del organismo operador en el momento, que de ser asunto prioritario en la agenda gubernamental. Es evidente que ninguno de los municipios le da un valor efectivo al Programa Cultura del Agua, lo que se observa en la escasa importancia otorgada en el organigrama y en el presupuesto. Si bien Monterrey se ha considerado ejemplar, las evidencias que muestran su efectividad no se pueden demostrar plenamente y al parecer la estrategia seguida va más enfocada a la comunicación efectiva que a la cultura del agua con todas sus connotaciones

Así, para los gobiernos, el programa representa algo que están obligados a cumplir, sin estar convencidos de su importancia o prioridad, y aun cuando hay casos más exitosos que otros esto ha sido en gran medida gracias al resultado del trabajo personal, que 
de una acción concertada entre las dependencias de gobierno involucradas. El PCA ha evidenciado los problemas observados en la administración local, como la falta de continuidad en los cargos, poca profesionalización y presupuesto bajo, por citar algunos.

Otra dificultad de fondo es la poca atención del gobierno federal; tampoco las gerencias generales y los organismos de cuenca han podido darle la misma importancia a este tema, en comparación con los indicadores de gestión del agua, que han sido más atendidos, pese a que este tipo de asuntos debería abordarse con personal especializado, presupuesto fijo y formas efectivas de medición, para que deje de ser un accesorio de los organismos operadores.

Recibido en octubre de 2009

Aceptado en marzo de 2010

\section{Bibliografía}

ANCA. 2009. Objeto social. http://www.aneas.com.mx/anca/objeto.htm (21 de septiembre de 2009).

BANDAN. 2008. Gestión local y financiera del agua para uso urbano en la frontera noreste México-Estados Unidos. Disco compacto.

Cohén, E., y R. Franco. 2003. Evaluación de proyectos sociales. México: Siglo xxI.

CCA. 2009. ¿Quiénes somos? http://www.aguas.org.mx/sitio/01c_ mision.html (8 de septiembre de 2009).

COMAPA-Nuevo Laredo. 2008. Programa de Cultura del Agua. http:// www.comapanuevolaredo.gob.mx/index_cultura.html (10 de marzo de 2008).

COMAPA-Reynosa. 2008. Programa de Cultura del Agua. http://www. comapareynosa.gob.mx/cultura/index.html (10 de marzo de 2008). 
CONAGUA. 2009a. Ley de Aguas Nacionales. Extracto para Programa Cultura del Agua. http://www.conagua.gob.mx/CONAGUA07/ Noticias/Extractolan04-CA.pdf (20 de agosto de 2009).

2009b. Modelo de convenio de coordinación del Programa Cultura del Agua 2009. http://www.conagua.gob.mx/ CONAGUA07/Noticias/ConveniopCA2009versiónFINALjulio.pdf (20 de agosto de 2009).

2009c. Modelo de anexo técnico 2009. http://www. conagua.gob.mx/CONAGUA07 / Noticias / AnexoTécnicopCA2009 versiónofinaljulio.pdf (20 de agosto de 2009).

2009d. Cultura del agua. http://www.conagua.gob.mx/ Espaniol/TmpContenido.aspx?id=90bc4a20-b2e8-4f95-9a0d6 fec7 $35516 \mathrm{~d} 4 \mid \% 20 \% 20 \% 20 \% 20 \% 20$ CULTURA $\% 20$ DEL $\% 20$ AGUA $|7| 0|0| 0 \mid 0$. (18 de agosto de 2009).

2009e. Manual de procedimientos y operación de programa federalizado Agua Limpia. http://www.conagua.gob.mx/ CONAGUA07/Noticias/Manual_Agua_Limpia_Fed2009.pdf (18 de agosto de 2009).

2008. Evaluación de consistencia y resultados 2007. Informe final del IMTA, marzo de 2008. http://www.conagua.gob. mx/CONAGUa07/Noticias/pal2007.pdf (15 de julio de 2009).

2007. Evaluación del Programa de Agua Limpia 2006. Evaluado por el Centro de Capacitación y Saneamiento del Agua. http://www.conagua.gob.mx/CONAGUA07/Noticias/PAL2006. pdf (15 de julio de 2009).

2006a. Evaluación del Programa Agua Limpia 2005. Evaluado por la Federación de Colegios de Ingenieros Civiles de la República Mexicana, A.C. http://www.conagua.gob.mx/ConAGUA07/Noticias/PaL2005.pdf (15 de julio de 2009). 
2006b. Resultados de la evaluación del programa de agua. http: / /www.conagua.gob.mx/CONAGUa07 / Noticias/paL20 06. pdf (15 de julio de 2009).

CONAGUA-SEMARNAT. 2008. Voces del tribunal de agua: entrevista a Heidi Storsberg Montes, coordinadora general de Atención Institucional, Comunicación y Cultura del Agua de la conagua. Boletín 8. (11 de agosto de 2008). http://www.conagua.gob.mx/ CONAGUA07 /Noticias/Boletin_8_final.pdf (10 de junio de 2009).

CONEVAL. 2008. Análisis de la difusión de las evaluaciones a los programas sociales por secretaría y entidad. http://www.coneval. gob.mx (6 abril de 2009).

CONOCER. 2009. Norma Técnica Labora, COAS0228.01: Difusión de la empresa de agua y saneamiento y promoción de la cultura del agua. http://www.conocer.gob.mx/Desarrollo/Buscadores_ Avanzados/pdf/COAs0228.01.pdf (22 de agosto de 2009).

Delgado, F., y J. Ramírez. 2008. Construyendo una cultura del agua en Perú: Estudio de percepción sobre el agua y hábitos de consumo en la población. http://www.wsp.org/UserFiles/file/Construyendo_una_cultura.pdf (10 de abril 2010).

DOF. 2004. Ley de Aguas Nacionales. 1 de diciembre de 1992. http://www.diputados.gob.mx/LeyesBiblio/pdf/16.pdf (8 de abril de 2009).

2003. Programas de Agua Potable, Alcantarillado y Saneamiento, Programa de Agua Potable, Alcantarillado y Saneamiento en Zonas Urbanas, Programa para la Construcción y Rehabilitación de Sistemas de Agua Potable y Saneamiento en Zonas Rurales y Programa de Agua Limpia. http://www.e-local.gob.mx/ work/sites/ELOCAL/resources/LocalContent/2116/1/agua_limpia.pdflocal.gob.mx/work/sites/ELOCAL/resources/LocalContent/2116/1/agua_limpia.pdf (2 de abril de 2010). 
EGAP. 2006. Cuaderno de mejores prácticas: Servicios de Agua y Drenaje de Monterrey, institución pública descentralizada.

EMM. Estado de Coahuila: Acuña. 2005a. http://www.e-local.gob. mx/wb2/ ELOCAL/EMM_coahuila (5 de febrero de 2008).

Estado de Nuevo León: Monterrey. 2005b. http:// www.e-local.gob.mx/work/templates/enciclo/nuevoleon/ municipios/19039a.htm (5 de febrero de 2008).

Estado de Tamaulipas: Nuevo Laredo. 2005c. http:// www. e-local.gob.mx/wb2/ELOCAL/EMM_tamaulipas (5 de febrero de 2008).

Estado de Tamaulipas: Reynosa. 2005d. http://www.elocal.gob.mx/wb2/ELOCAL/EMM_tamaulipas (5 de febrero de 2008).

González, G. E. 2003. ¿Para qué una cultura del agua? Agua y desarrollo sustentable.

IMTA. 2010. PIGOO indicadores de gestión de organismos operadores. http: / /www.pigoo.gob.mx/index.php?option=com_content\& view $=$ article\&id $=70 \& I t e m i d=3$ (8 de abril de 2010).

INE-SEMARNAT. 1998. Reporte del estado ambiental y de los recursos naturales de la frontera norte de México.

Ley deAgua del Estado deTamaulipas. 2009. http://200.23.59.155/ html/legisla/leyes/leyes04.pdf (8 de abril de 2009).

Ley de Agua para los Municipios del Estado de Coahuila de Zaragoza. 2009. http://www.congresocoahuila.gob.mx/index.cfm/ mod.legislacion_archivo/dir.LeyesEstatalesVigentes/index.coah (8 de abril de 2009). 
Ley de Agua Potable y Saneamiento del Estado de Nuevo León. 2009. http://ferrerosoftware.com/ADMTeca/docs/AGUA\%20POTABLE\%20Y\%20SANEAMIENTO.pdf (8 de abril de 2009).

Murillo Ortega, Rosendo. 2006. La cultura del agua: un compromiso común/entrevista. Conciencia Tecnológica 014: 34-36.

OMs. 2010. La cantidad de agua domiciliaria, el nivel de servicio y la salud. http://www.who.int/water_sanitation_health/diseases/ wsh0302/es/index.html (15 de abril de 2010).

Pacheco, V. R. 2005. Cultura del agua: más allá de los discursos de escasez y contaminación. Aquaforum 9 (40): 1-2. http://seia. guanajuato.gob.mx/document/AquaForum/AF40/af40_05Cul turadelAguaMasalladelosDiscursos.pdf (12 de abril de 2009).

PNH 2007-2012. 2008. Objetivo 5: Consolidar la participación de los usuarios y la sociedad organizada en el manejo del agua y promover la cultura de su buen uso. http://www.conagua.gob. mx/CONAGUA07/Noticias/PNH_07_08.pdf (13 de septiembre de 2009).

Sandoval, R. M., S. J. Montoya y G. E. Jiménez. 2002. La cultura del agua en la creación de las capacidades para la gestión descentralizada del agua. El caso de Guanajuato, México. http://www.fnca. eu/fnca/america/docu/1719.pdf (3 de abril de 2010).

SADM. 2008. Cultura del agua. http://www.sadm.gob.mx/sadm/ jsp/seccion.jsp?id=217 (14 de marzo de 2008).

SEMARnat. 2009. Capítulo 10. Balance de la evolución institucional del sector hídrico. http://www.cambioclimaticoyseguridadnacional.org/biblioteca/11574129569019.pdf (21 de mayo de 2009).

SIMAS Acuña. 2008. Cultura del agua. http://www.simas.org/cultura/index.html (14 de abril de 2009). 
Subirats, Joan. 1995. Los instrumentos de las políticas, el debate público y el proceso de evaluación. Revista Gestión y Política Pública IV (1): 5-23.

UNESCO. 2008. Cultura del agua. http://www.unesco.org.uy/phi/ aguaycultura/es/inicio/cultura-del-agua.html (15 de julio de 2008).

Vargas, Ramón. 2006. La cultura del agua. Lecciones de la América indígena. Serie Agua y Cultura no. 1, Programa Hídrico Internacional, UNESCO para América Latina y el Caribe.

Ziccardi, A., y H. Saltalamacchia. 1997. Metodología de evaluación del desempeño de los gobiernos locales en ciudades mexicanas. México: Instituto de Investigaciones Sociales de la Universidad Nacional Autónoma de México. 